\title{
Covid-19: GPs call for appraisals and CQC inspections to be suspended
}

\author{
Abi Rimmer
}

The BMJ

GP leaders have called for assurances that they will not face contractional sanctions if a covid-19 pandemic forces them to suspend normal practice.

Delegates attending a special conference of local medical committees, held in London on 11 March, unanimously voted in favour of a motion that called on the BMA's General Practitioners Committee in England to negotiate changes to protect practices in the event of a covid-19 pandemic.

The motion called for funding from the quality and outcomes framework (QOF) and directed enhanced services to be used to fund essential services and for any additional costs accrued by practices related to covid-19 infections to be reimbursed. It said that practices should be able to "prioritise frontline work and suspend other requirements including appraisals and CQC [Care Quality Commission] inspections.”

The motion, put forward by Michelle Drage, chief executive of Londonwide LMCs, also said that no contractual sanctions or remedial or breach notices should be issued to practices "as a result of the forced change to normal practice while the national emergency persists."

Responding to the motion, Mark Sanford-Wood, deputy chair of the General Practitioners Committee, said that the committee was in daily contact with NHS England, Public Health England, and the Royal College of General Practitioners to talk about covid-19.

"We are in active discussions around a whole range of issues including, but not limited to, QOF suspension, the supply of PPE [personal protective equipment], and the preferential testing of frontline healthcare professionals-so that we can get back into the workforce as soon as possible."

Sanford-Wood said that the committee was also discussing sick pay and death in service benefits for locums. The NHS pension scheme provides a lump sum and pension benefits to doctors' dependants in the event of their death. But some locum GPs are not eligible for this benefit. ${ }^{1}$

He added, "We're looking at provisions for suspending services in certain circumstances, and we're looking at the governance around retirees coming back and how that can be done safely. We're also looking at discussing with NHS England the regular and clear communications that need to be produced for both the public and the profession."

Speaking to The BMJ after the motion was passed, Drage said, "Clearly covid-19 is going to be around for some time and we can't, as GPs and practices, look after our patients and look after our staff if we are chasing bits of bureaucracy or providing care that is more than essential."

She added, "We have to batten down the hatches and provide the care that patients need, which is defined in essential services. Because there is more care that needs to be provided with potentially fewer staff, we need to have the flexibility in our contracts to be able to get on with it and use whatever funding we've got to meet that need."

Ian Trenholm, chief executive of the CQC, said in a statement that its inspection and regulation activity would continue. "However, we will be adapting our standard inspection approach—adopting a targeted risk based approach to direct our efforts at areas of specific safety concern-this means that planned inspections of services may well be postponed," he said.

He added that clinically qualified CQC special advisers were already being supported to return to the frontline to help with the wider national response.

1 Rimmer A. Locum GPs must have same death in service benefits as other doctors, say LMCs. BMJ 2019:364:11331, 10.1136/bmj 1133130898788

Published by the BMJ Publishing Group Limited. For permission to use (where not already granted under a licence) please go to http://group.bmj.com/group/rights-licensing/ permissions 